\title{
Repository corticotropin injection in patients with rheumatoid arthritis resistant to biologic therapies
}

This article was published in the following Dove Press journal: Open Access Rheumatology: Research and Reviews

\section{Peter A Fischer' \\ Ronald J Rapoport ${ }^{2}$}

'Sturdy Memorial Hospital, Attleboro, MA, USA; ${ }^{2}$ Division of Rheumatology, Southcoast Health, Fall River, MA, USA
Correspondence: Peter A Fischer Mansfield Health Center, 200 Copeland Drive, Mansfield, MA 02048, USA

Tel +l $5083394 \mid 44$

Fax +I 5083391966

Email pcfischer@comcast.net
Introduction: Although synthetic and biologic disease-modifying antirheumatic drugs are available, many patients with rheumatoid arthritis have a difficult-to-control disease and need other treatment options. Repository corticotropin injection (RCI) may alleviate symptoms and exacerbations in patients with refractory disease.

Methods: Nine patients with refractory rheumatoid arthritis were included in this study. Patients were maintained on their baseline therapies with a minimum of $7.5 \mathrm{mg}$ prednisone daily. RCI was given daily at $40 \mathrm{U}$ for 7 days. Patients who had an adequate disease response were given $40 \mathrm{U}$ twice weekly through Week 12 . For patients who had inadequate disease response, the dose was increased to $80 \mathrm{U}$ daily for 7 days, followed by $80 \mathrm{U}$ twice weekly through Week 12 . Results: The primary endpoint was $>1.2$ point reduction in the Disease Activity Score 28 using C-reactive protein (DAS28-CRP) at Week 12. Secondary endpoints were improvements in Health Assessment Questionnaire-Disease Index and Functional Assessment of Chronic Illness Therapy scores. Six of the nine patients met the primary endpoint. The average change in DAS28-CRP from baseline to Week 12 was numerically greater with $40 \mathrm{U}$ than with $80 \mathrm{U}$ RCI. Functional Assessment of Chronic Illness Therapy and Health Assessment Questionnaire-Disease Index improved as early as Week 1, and the improvements remained throughout treatment.

Conclusion: There was no association between cortisol levels and low-dose RCI response. No serious adverse events occurred. RCI produced a clinically meaningful reduction in markers of disease activity, improved health-related quality of life, and a favorable safety profile. The response rate to RCI was substantial and shows promise in this difficult-to-treat population.

Keywords: repository corticotropin injection, rheumatoid arthritis, Disease Activity Score 28 using C-reactive protein (DAS28-CRP), health-related quality of life, biologic failure, melanocortin, refractory rheumatoid arthritis

\section{Introduction}

Rheumatoid arthritis (RA) is a chronic inflammatory disorder. ${ }^{1}$ It is characterized by synovial inflammation, joint swelling, tenderness, and stiffness. This can lead to bone erosion, cartilage damage, and joint destruction that result in substantial disability.

RA is a disease with serious financial and health impact. Approximately 1.5 million adults in the USA are diagnosed with RA. ${ }^{2}$ From 1997 to 2005, annual medical care expenditures among US adults with arthritis increased by $\$ 100$ billion. ${ }^{3}$ In 2008 alone, the adjusted average annual total expenditure per patient for RA in the USA was $\$ 13,012 .{ }^{4}$ Additionally, in a retrospective database analysis, societal costs for RA in the USA, including intangible costs, were estimated to be $\$ 39.2$ billion. ${ }^{5}$ Active RA 
is associated with excess morbidity, including cardiovascular disease, type 2 diabetes, and malignancies (lymphoma). ${ }^{6-8}$

The primary goal of therapy is to manage inflammation and disease activity. ${ }^{1,9}$ Treatment options for RA include the following: glucocorticoids, which decrease inflammation and reduce immune system activity, but are limited by a high side effect profile; conventional synthetic disease-modifying antirheumatic drugs (csDMARDs), which slow the progression of joint damage by influencing the immune system; and biologic DMARDs (bDMARDs), which are produced by recombinant DNA technology and generally target cytokines, their receptors, or other cell surface molecules. ${ }^{1,10}$

Despite the availability of csDMARDs and bDMARDs, RA does not respond to treatment in many patients and remains inadequately controlled. ${ }^{9}$ Repository corticotropin injection (RCI), a highly purified porcine analog of adrenocorticotropic hormone (ACTH), ${ }^{11}$ may benefit patients with refractory RA. Similar to ACTH, RCI stimulates the adrenal cortex to secrete cortisol, corticosterone, aldosterone, and a number of weak androgenic substances. ACTH is a member of the melanocortin family of peptides. ${ }^{12}$ ACTH not only exerts steroidogenic effects by interacting with the melanocortin 2 receptor $\left(\mathrm{MC}_{2} \mathrm{R}\right)$ in the adrenal cortex, but also has nonsteroidogenic effects. This is apparent in its interactions with receptors found on immune cells, osteoblasts, osteoclasts, and cells of the synovium. ${ }^{12-14}$ It has been shown that ACTH binds to all five known melanocortin receptors $\left(\mathrm{MC}_{1-5} \mathrm{R}\right)$, which suggests ACTH may possess anti-inflammatory and immunomodulatory effects by activating the other MCRs in addition to $\mathrm{MC}_{2} \mathrm{R}$.

Through these pathways, RCI may ameliorate disease symptoms. Even short treatment with RCI may impact disease progression as it has been shown that a 5-day course of intramuscular or subcutaneous RCI improved the symptoms associated with acute exacerbations of multiple sclerosis. ${ }^{15}$ A claims-based analysis of patients with RA, systemic lupus erythematosus, dermatomyositis, and polymyositis demonstrated that RCI use may be linked to a significant decrease in corticosteroid requirements. ${ }^{16}$ Based on these data, it is possible that RCI in combination with csDMARDs and bDMARDs may provide relief from RA and ameliorate acute exacerbations of RA in patients with disease that is inadequately controlled by these therapeutic agents alone.

\section{Patients and methods}

The objective of this study was to assess the efficacy and safety of adjunctive RCI treatment in patients with active RA who have had an inadequate response to csDMARDs and at least three bDMARDs (including one tumor necrosis factor inhibitor). This was a 12-week observational, prospective, multicenter, open-label study conducted in two private practices in the USA. Patients were screened for eligibility within 5 days prior to study initiation. Patients were eligible if they had active disease, which was defined as $\geq 6$ swollen joints, $\geq 6$ tender joints, and C-reactive protein (CRP) levels and/or erythrocyte sedimentation rate $\geq 1.2$ times the upper limit of normal. Patients were taking stable doses of csDMARDs and bDMARDs for 3 months and stable doses of nonsteroidal anti-inflammatory drugs, prednisone, or equivalent dose of corticosteroid ( $\geq 7.5 \mathrm{mg} /$ day), and analgesics for 28 days prior to screening.

A total of $40 \mathrm{U}$ RCI ( $80 \mathrm{USP}$ units $/ \mathrm{mL}$ ) was administered subcutaneously daily for 7 days as adjunctive therapy. After 1 week, doses were adjusted based on response. An adequate response was defined as $>1.2$ point reduction in the Disease Activity Score 28 using CRP (DAS28-CRP). ${ }^{17}$ If an adequate response was achieved, patients were given $40 \mathrm{U}$ RCI twice weekly through Week 12 . If the response was inadequate, patients received $80 \mathrm{U}$ RCI daily for 7 days, followed by 80 U twice weekly through Week 12 .

The primary endpoint was an adequate response of $>1.2$ point reduction in DAS28-CRP at Week 12 compared with baseline. Secondary endpoints included a decrease in Health Assessment Questionnaire-Disease Index (HAQ-DI) ${ }^{18}$ and an increase in Functional Assessment of Chronic Illness Therapy (FACIT) ${ }^{19}$ scores. Cortisol levels were also assessed at study visits.

The nature, incidence, and severity of adverse events (AEs) and serious adverse events (SAEs) were monitored after administration of RCI and throughout the study. AEs were documented, evaluated, and treated by the principal investigator according to a standard of care. The AEs were also reported to the Institutional Review Board (IRB) and Mallinckrodt Pharmaceuticals (the manufacturer of RCI) within 5 business days. All SAEs were reported to the IRB and Mallinckrodt within $24 \mathrm{~h}$.

Written informed consent was obtained from all patients prior to study initiation. IRB approval was obtained at each investigator's institution (Dr Fischer: Sturdy Memorial Hospital Institutional Review Board, Attleboro MA; Dr Rapoport: Shulman IRB, Research Triangle Park, NC). This study is registered at ClinicalTrials.gov (NCT02434757).

\section{Results}

A total of nine patients with active RA were maintained on stable doses of csDMARDs, bDMARDs, and prednisone 
(minimum of $7.5 \mathrm{mg}$ daily). The patients (four women and five men; age range 44-62 years) had an average RA history of 11.7 years (Table 1 ). After 1 week of therapy, five of the nine patients had improvements in DAS28-CRP and continued to receive $40 \mathrm{U}$ RCI (patients 2, 3, 6, 8, and 9), while the remaining four patients were dose escalated to $80 \mathrm{U}$ RCI (patients 1, 4, 5, and 7). Six of the nine patients (patients 2, 3, 5, 6, 8, and 9) met the primary endpoint (Figure 1), including all five in the $40 \mathrm{U}$ RCI group and one from the $80 \mathrm{U}$ RCI group. Two patients dropped out of the study due to inadequate response (patients 1 and 7). The mean DAS28-CRP improvement at 12 weeks (change in DAS28-CRP from baseline to Week 12) among patients on $40 \mathrm{U}$ of therapy $(-1.994)$ was numerically greater than that in patients increasing their dose to $80 \mathrm{U}(-1.635$; Figure 2$)$.

There were also improvements in secondary endpoints. Both FACIT and HAQ-DI changes were evident as early as Week 1 and improvements remained consistent through Week 12 (Figure 2). Four of the nine patients (patients 2, 5, 6, and 8) maintained improvement in both HAQ-DI and FACIT scores at Week 12 compared with baseline, while one (patient 9) maintained improvement in HAQ-DI score only (Figure 1).

Cortisol levels did not increase at Week 1 , even with daily dosing of RCI (Table 2); no clear association was noted between cortisol levels and RCI response. Of the four patients who had an RCI dose increase to $80 \mathrm{U}$, three had cortisol data available beyond Week 1 , two of whom had a prominent increase in cortisol levels.

No SAEs occurred. AEs recorded in the study included cushingoid features $(n=2)$, mild hyperglycemia $(n=1)$, herpes zoster $(n=1)$, and pedal edema $(n=1)$.

\section{Discussion}

Our study reinforces the effectiveness of RCI treatment in patients with active RA. ${ }^{20}$ Of the nine patients treated with $\mathrm{RCI}$, five responded to $40 \mathrm{U}$ daily for 1 week and did not need a dose increase (patients 2, 3, 6, 8, and 9). One patient in the $80 \mathrm{U}$ group had clinically significant improvement (patient 5). Four of the five patients on $40 \mathrm{U}$ RCI showed improvement in HAQ-DI score (patients 2, 6, 8, and 9) and one showed no change (patient 3 ). Of the four patients on $80 \mathrm{U} \mathrm{RCI}$, one showed improvement (patient 5), two dropped out (patients 1 and 7), and one patient's HAQ-DI score declined (patient 4). At Week 12, all but one patient on $40 \mathrm{U}$ RCI showed improvement in FACIT (patient 9). Of the patients taking $80 \mathrm{U} \mathrm{RCI}$, only one showed improvement in FACIT score (patient 5).

Our study - although not double blinded or placebo controlled - is one of the few prospective studies on the effect

Table I Patient demographics

\begin{tabular}{|c|c|c|c|c|c|c|c|c|c|c|}
\hline Patient No. & I & 2 & 3 & 4 & 5 & 6 & 7 & 8 & 9 & Average \\
\hline Age (years) & 51 & 62 & 52 & 60 & 44 & 51 & 45 & 49 & 53 & 51.9 \\
\hline Gender & $\mathrm{F}$ & $M$ & $\mathrm{~F}$ & $M$ & $M$ & $M$ & $\mathrm{~F}$ & $\mathrm{~F}$ & $M$ & NA \\
\hline RF & + & - & - & + & - & - & + & - & + & NA \\
\hline ACPA & + & - & - & + & - & - & + & - & + & NA \\
\hline Duration of RA (years) & 29 & II & II & 3 & 5 & 30 & 8 & 5 & 3 & II.7 \\
\hline \multirow[t]{9}{*}{ DMARD history } & ADA & $\mathrm{ABA}$ & ADA & ADA & $\mathrm{ABA}$ & $\mathrm{ABA}$ & $\mathrm{ABA}$ & ADA & $\mathrm{ABA}$ & NA \\
\hline & ETN & ADA & RTX & RTX & ADA & AUR & ETN & ANA & GLB & \\
\hline & SSZ & CEP & & SSZ & ETN & AZA & CEP & ETN & ETN & \\
\hline & & ETN & & $\mathrm{TCZ}$ & & CSA & $\mathrm{TCZ}$ & MTX & $\mathrm{HCQ}$ & \\
\hline & & RTX & & & & ETN & & RTX & $\mathrm{TCZ}$ & \\
\hline & & $\mathrm{TCZ}$ & & & & $\mathrm{HCQ}$ & & TOF & & \\
\hline & & & & & & MTX & & $\mathrm{TCZ}$ & & \\
\hline & & & & & & PRO & & & & \\
\hline & & & & & & SSZ & & & & \\
\hline \multirow[t]{2}{*}{ Current DMARDs } & CEP & MTX & $\mathrm{ABA}$ & MTX & MTX & ANA & INX & ABA & MTX & NA \\
\hline & & TOF & MTX & TOF & $\mathrm{TCZ}$ & & MTX & & RTX & \\
\hline Baseline DAS28-CRP & 6.49 & 5.99 & 5.36 & 5.29 & 5.17 & 5.78 & 4.07 & 6.02 & 4.02 & 5.35 \\
\hline Baseline CRP (mg/L) & 45 & 19.6 & 3.5 & 6 & 3 & 54.9 & I I.7 & 24.2 & 23 & 21.21 \\
\hline Baseline ESR $(\mathrm{mm} / \mathrm{h})$ & 104 & 6 & 5 & 21 & 46 & 4 & 66 & 45 & 3 & 33.33 \\
\hline Tender joints (28 count) & 12 & 13 & 15 & 10 & 20 & 12 & 4 & 15 & 7 & 12.00 \\
\hline Swollen joints (28 count) & 13 & 13 & 6 & 10 & 7 & 7 & 3 & 8 & 6 & 8.11 \\
\hline Prednisone dose (mg) & 7.5 & 7.5 & 10 & 7.5 & 7.5 & 7.5 & 10 & 10 & 7.5 & 8.33 \\
\hline
\end{tabular}

Abbreviations: ABA, abatacept; ACPA, anti-citrullinated protein antibody; ADA, adalimumab; ANA, anakinra; AUR, auranofin; AZA, azathioprine; CEP, certolizumab pegol; CRP, C-reactive protein; CSA, cyclosporine; DAS28-CRP, Disease Activity Score 28 using C-reactive protein; DMARD, disease-modifying antirheumatic drug; ESR, erythrocyte sedimentation rate; ETN, etanercept; F, female; GLB, golimumab; HCQ, hydroxychloroquine; INX, infliximab; M, male; MTX, methotrexate; NA, not applicable; PRO, prosorba column; RA, rheumatoid arthritis; RF, rheumatoid factor; RTX, rituximab; SSZ, sulfasalazine; TCZ, tocilizumab; TOF, tofacitinib. 
DAS28-CRP

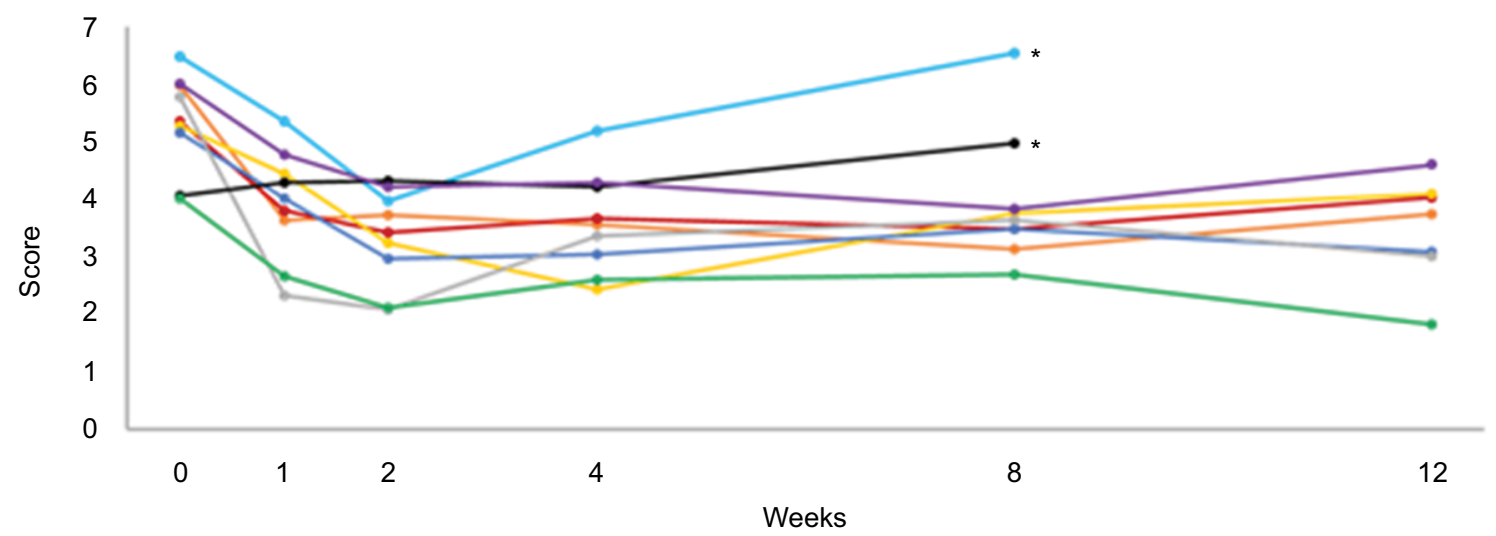

HAQ-DI

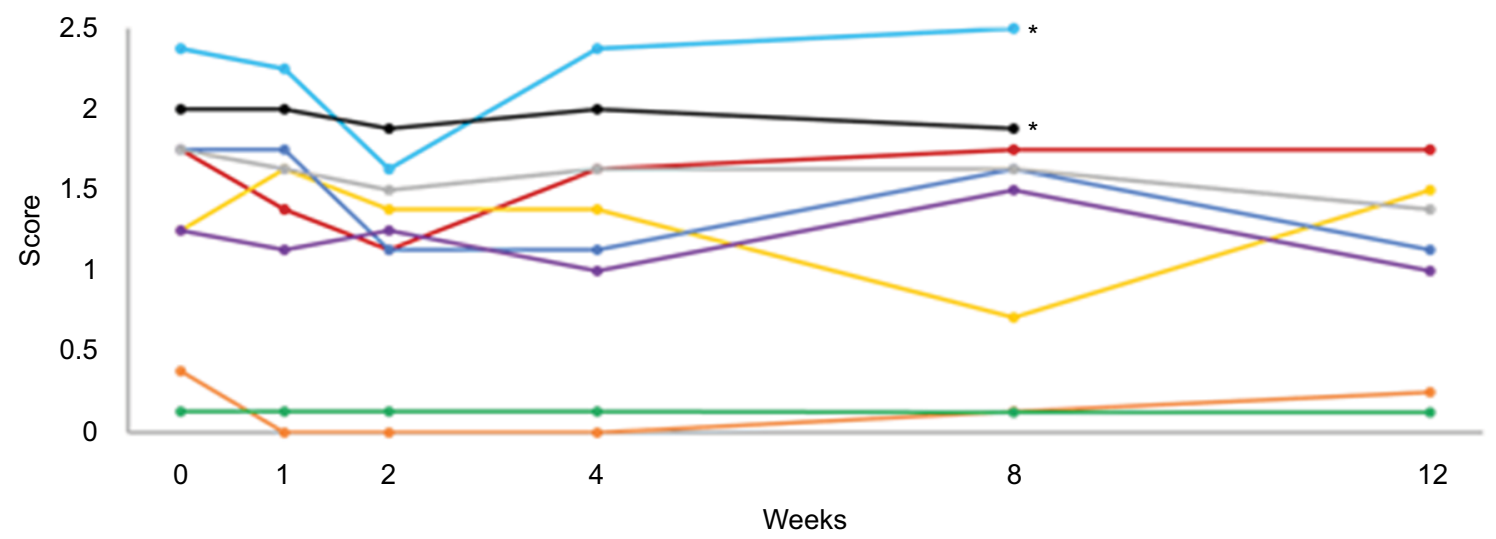

FACIT

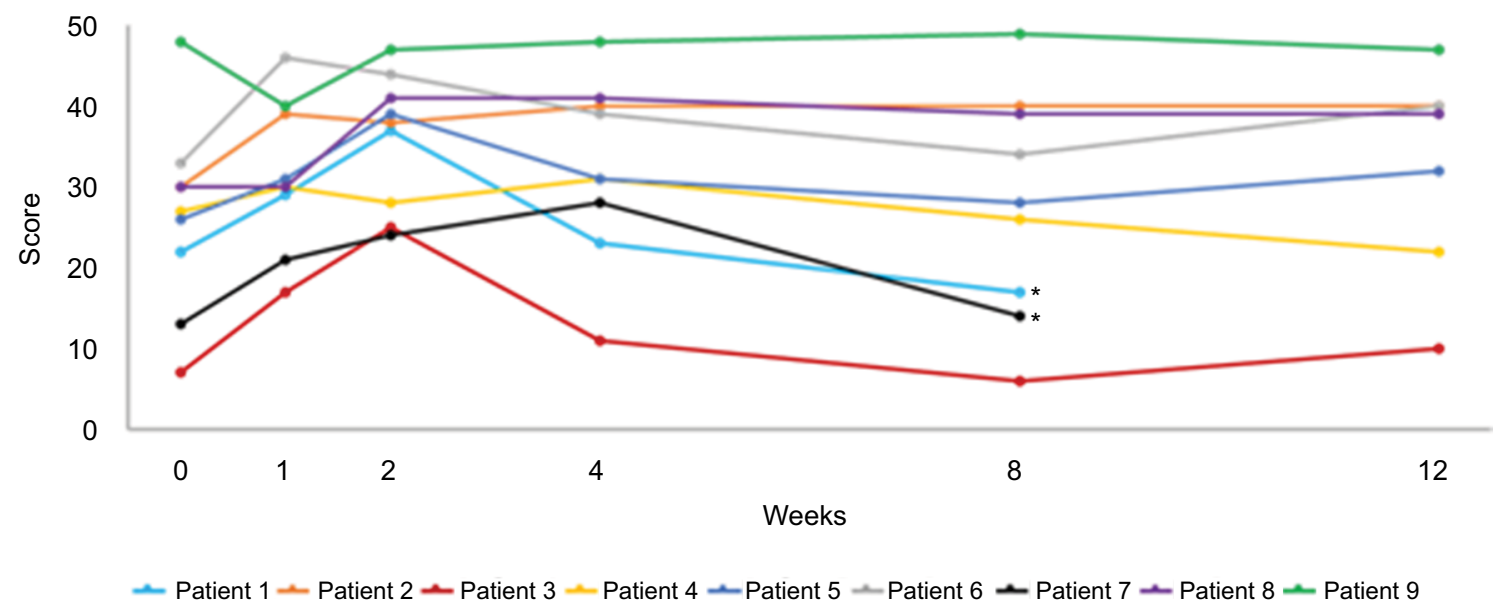

Figure I Individual response to $\mathrm{RCl}$ from baseline through Week 12 .

Notes: Patients I, 4, 5, and 7 were on $40 \cup \mathrm{RCl}$ for Week I, which was then increased to $80 \mathrm{U} \mathrm{RCl}$ for Week 2. Patients 2, 3, 5, 6, 8, and 9 met the primary endpoint (>I.2 point reduction in DAS28-CRP at Week 12 compared with baseline). Patients 2, 5, 6, 8, and 9 maintained improvement in HAQ-DI and FACIT scores at Week 12 compared with weeks I and 2. *Patients I and 7 dropped out of the study due to inadequate response. A decrease in DAS28-CRP and HAQ-DI and an increase in FACIT indicate improvement.

Abbreviations: DAS28-CRP, Disease Activity Score 28 using C-reactive protein; FACIT, Functional Assessment of Chronic Illness Therapy; HAQ-DI, Health Assessment Questionnaire-Disease Index; $\mathrm{RCl}$, repository corticotropin injection.

of RCI treatment in RA. This study suggests that $40 \mathrm{U}$ RCI daily followed by $40 \mathrm{U}$ twice weekly is an effective treatment for patients with refractory RA. Although higher-dose
RCI and corticosteroids may share a side effect profile, all new AEs were mild AEs. Dose escalations increased the risk of mild AEs, while not increasing the clinical benefit 

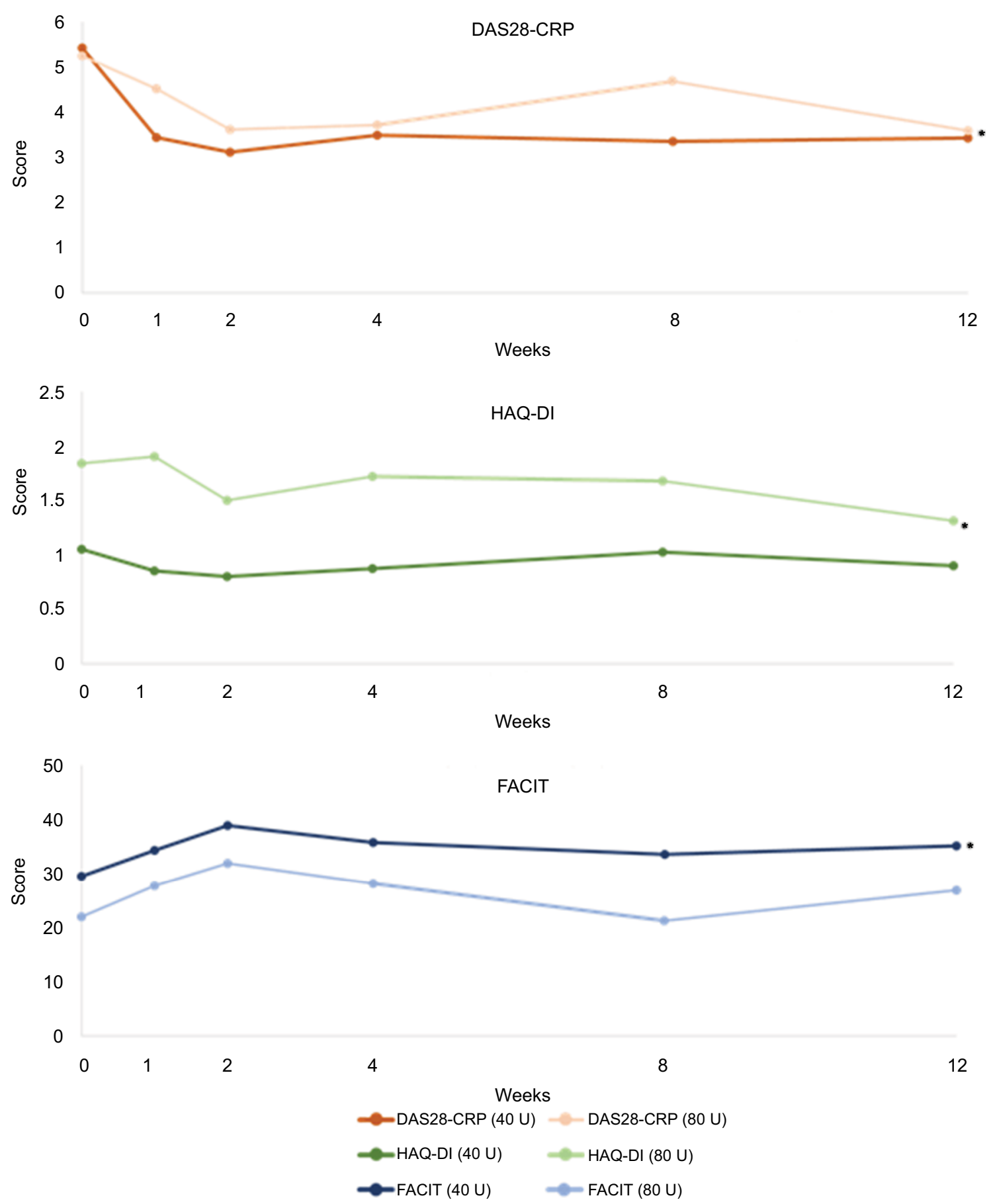

Figure 2 Average response to $\mathrm{RCl}$ from baseline to Week 12 .

Notes: All patients were initiated on $40 \mathrm{U} \mathrm{RCl}$ daily. If an adequate response (>I.2 point reduction in the DAS28-CRP) was achieved at Week I, the dose was decreased to $40 \mathrm{U}$ twice weekly through Week 12. If the response was inadequate at Week I, patients received $80 \mathrm{U} \mathrm{RCl}$ once daily for 7 days, followed by $80 \mathrm{U}$ twice weekly through Week 12. A decrease in DAS28-CRP and HAQ-DI and an increase in FACIT indicate improvement. *Data for two patients are not reported here as they dropped out due to inadequate response (patients $I$ and 7$)$.

Abbreviations: DAS28-CRP, Disease Activity Score 28 using C-reactive protein; FACIT, Functional Assessment of Chronic Illness Therapy; HAQ-DI, Health Assessment Questionnaire-Disease Index; $\mathrm{RCl}$, repository corticotropin injection.

in a majority of patients. Perhaps the mechanism of action of RCI is not dependent on dosing as long as a minimum threshold is met.

These patients had active, severe RA and were unresponsive to three bDMARDs; for this reason, they were maintained on a minimum prednisone dose of $7.5 \mathrm{mg} /$ day. Cortisol levels did not increase after daily dosing of RCI (Week 1). It is possible that cortisol levels did not increase due to lower doses of RCI not having an affect on the adrenal glands, or because some of the patients were adrenally 
Table 2 Cortisol levels (ug/DL)

\begin{tabular}{|c|c|c|c|c|c|c|c|}
\hline Patient & Dose (U) & Baseline & Week I & Week 2 & Week 4 & Week 8 & Week I2 \\
\hline 1 & 80 & 3.70 & 2.60 & 19.9 & $*$ & $*$ & $\#$ \\
\hline 2 & 40 & 22.0 & 22.3 & 21.5 & $*$ & $*$ & 29.2 \\
\hline 3 & 40 & 20.6 & 24.3 & 20.1 & 20.6 & 23.0 & 13.8 \\
\hline 4 & 80 & $*$ & 13.5 & 47.1 & 23.4 & $*$ & 17.0 \\
\hline 5 & 80 & 16.3 & 17.0 & 10.0 & 13.4 & $*$ & 11.8 \\
\hline 6 & 40 & 10.3 & 6.70 & 7.00 & 7.70 & $*$ & 8.80 \\
\hline 7 & 80 & 7.70 & 6.30 & $*$ & $*$ & $*$ & $\#$ \\
\hline 8 & 40 & 6.60 & 2.40 & 20.7 & $*$ & $*$ & 0.70 \\
\hline 9 & 40 & 11.2 & 7.70 & 9.90 & 38.7 & 7.20 & 9.40 \\
\hline
\end{tabular}

Notes: Patients I, 4, 5, and 7 were on $40 \cup \mathrm{RCl}$ for Week I, which was then increased to $80 \mathrm{U} \mathrm{RCl}$ for Week 2. *Data not collected. \#Data not reported here as patient dropped out due to inadequate response.

Abbreviation: $\mathrm{RCl}$, repository corticotropin injection.

suppressed. As dose escalation did not reliably decrease disease activity or increase cortisol levels in all patients, this suggests a mechanism of action for RCI besides steroidogenesis. In our study, interpretation of cortisol levels is challenging because patients were maintained on a daily dose of prednisone. Further placebo-controlled studies in patients not receiving prednisone are needed to fully understand the mechanisms of RCI.

\section{Conclusion}

RCI produced a clinically meaningful reduction in markers of disease activity, improved quality of life (as assessed by HAQ-DI), and demonstrated a favorable safety profile. Cortisol levels did not seem to correlate with clinical response. Also, $40 \mathrm{U}$ RCI twice weekly is an effective RA treatment as shown by the response rate. The response rate was numerically lower in the $80 \mathrm{U}$ RCI treatment group; however, this may be due to the patients who were dose escalated, representing nonresponders to treatment with RCI. For patients who are refractory to common RA treatment, the response rate to RCI was substantial and shows great promise in this difficult-to-treat population.

\section{Acknowledgments}

Funding for the study was provided by Mallinckrodt Pharmaceuticals. The data contained in this manuscript were previously presented at the Federation of Clinical Immunology Societies' (FOCIS) 2016 Annual Meeting and published in Annals of the Rheumatic Diseases as an abstract http://ard. bmj.com/content/75/Suppl_2/1041.2.

\section{Disclosure}

Dr Fischer has received grants for research support from Genentech and AbbVie. The authors report no other conflicts of interest in this work.

\section{References}

1. Singh JA, Cameron DR. Summary of AHRQ's comparative effectiveness review of drug therapy for rheumatoid arthritis (RA) in adults-an update. J Manag Care Pharm. 2012;18(4 Supp C):S1-S18.

2. Myasoedova E, Crowson CS, Kremers HM, Therneau TM, Gabriel SE. Is the incidence of rheumatoid arthritis rising? Results from Olmsted County, Minnesota, 1955-2007. Arthritis Rheum. 2010;62(6):1576-1582.

3. Cisternas MG, Murphy LB, Yelin EH, Foreman AJ, Pasta DJ, Helmick CG. Trends in medical care expenditures of US adults with arthritis and other rheumatic conditions 1997 to 2005. J Rheumatol. 2009;36(11):2531-2538.

4. Kawatkar AA, Jacobsen SJ, Levy GD, Medhekar SS, Venkatasubramaniam KV, Herrinton LJ. Direct medical expenditure associated with rheumatoid arthritis in a nationally representative sample from the medical expenditure panel survey. Arthritis Care Res (Hoboken). 2012;64(11):1649-1656.

5. Birnbaum H, Pike C, Kaufman R, Marynchenko M, Kidolezi Y, Cifaldi M. Societal cost of rheumatoid arthritis patients in the US. Curr Med Res Opin. 2010;26(1):77-90.

6. Dregan A, Charlton J, Chowienczyk P, Gulliford MC. Chronic inflammatory disorders and risk of type 2 diabetes mellitus, coronary heart disease, and stroke: a population-based cohort study. Circulation. 2014;130(10):837-844.

7. Baecklund E, Iliadou A, Askling J, et al. Association of chronic inflammation, not its treatment, with increased lymphoma risk in rheumatoid arthritis. Arthritis Rheum. 2006;54(3):692-701.

8. Goodson N, Marks J, Lunt M, Symmons D. Cardiovascular admissions and mortality in an inception cohort of patients with rheumatoid arthritis with onset in the 1980s and 1990s. Ann Rheum Dis. 2005;64(11):1595-1601.

9. Davis JM 3rd, Matteson EL, American College of Rheumatology; European League Against Rheumatism. My treatment approach to rheumatoid arthritis. Mayo Clin Proc. 2012;87(7):659-673.

10. Singh JA, Furst DE, Bharat A, et al. 2012 update of the 2008 American College of Rheumatology recommendations for the use of diseasemodifying antirheumatic drugs and biologic agents in the treatment of rheumatoid arthritis. Arthritis Care Res (Hoboken). 2012;64(5):625-639.

11. H.P. Acthar Gel [package insert]. Hazelwood, MO: Mallinckrodt ARD, Inc; revised January 2015. Available from: http://www.acthar.com/pdf/ Acthar-PI.pdf. Accessed January 13, 2017.

12. Catania A, Gatti S, Colombo G, Lipton JM. Targeting melanocortin receptors as a novel strategy to control inflammation. Pharmacol Rev. 2004;56(1):1-29.

13. Bohm M, Grassel S. Role of proopiomelanocortin-derived peptides and their receptors in the osteoarticular system: from basic to translational research. Endocr Rev. 2012;33(4):623-651.

14. Zhong Q, Sridhar S, Ruan L, et al. Multiple melanocortin receptors are expressed in bone cells. Bone. 2005;36(5):820-831. 
15. Simsarian JP, Saunders C, Smith DM. Five-day regimen of intramuscular or subcutaneous self-administered adrenocorticotropic hormone gel for acute exacerbations of multiple sclerosis: a prospective, randomized, open-label pilot trial. Drug Des Devel Ther. 2011;5:381-389.

16. Myung G, Nelson W, McMahon MA. Effects of repository corticotropin injection on medication use in patients with rheumatologic conditions: a claims data study. Rheum Arthritis. 2016;68(1):2896-2898.

17. Wells G, Becker JC, Teng J, et al. Validation of the 28 -joint disease activity score (DAS28) and European league against rheumatism response criteria based on C-reactive protein against disease progression in patients with rheumatoid arthritis, and comparison with the DAS28 based on erythrocyte sedimentation rate. Ann Rheum Dis. 2009;68(6):954-960.
18. Bruce B, Fries JF. The Stanford Health Assessment Questionnaire: a review of its history, issues, progress, and documentation. J Rheumatol. 2003;30(1):167-178.

19. Webster K, Cella D, Yost K. The functional assessment of chronic illness therapy (FACIT) measurement system: properties, applications, and interpretation. Health Qual Life Outcomes. 2003;1:79.

20. Gillis T, Crane M, Hinkle C, Wei N. Repository corticotropin injection as adjunctive therapy in patients with rheumatoid arthritis who have failed previous therapies with at least three different modes of action. Open Access Rheumatol. 2017;9:131-138.
Open Access Rheumatology: Research and Reviews

\section{Publish your work in this journal}

Open Access Rheumatology: Research and Reviews is an international, peerreviewed, open access journal publishing original research, reports, editorials, reviews and commentaries on all aspects of clinical and experimental rheumatology in the clinic and laboratory including the following topics: Pathology, pathophysiology of rheumatological diseases; Investigation, treatment and

\section{Dovepress}

management of rheumatological diseases; Clinical trials and novel pharmacologi$\mathrm{cal}$ approaches for the treatment of rheumatological disorders. The manuscript management system is completely online and includes a very quick and fair peer-review system, which is all easy to use. Visit http://www.dovepress.com/ testimonials.php to read real quotes from published authors. 